Proceedings of SALT 24: 255-270, 2014

\title{
Plural indefinite articles: The case of unos and des *
}

\author{
Bert Le Bruyn \\ Utrecht Institute of Linguistics \\ Julia Pozas-Loyo \\ El Colegio de México
}

\begin{abstract}
Plurality typically comes in two flavors: an inclusive and an exclusive one. We exploit these different plurality 'flavors' to argue that there are two types of plural indefinite articles, each with their own characteristics with respect to 'blocking' and aspect. We argue that French des instantiates the 'inclusive' plural indefinite article and Spanish unos the 'exclusive' plural indefinite article.
\end{abstract}

Keywords: indefinite article, blocking, unos, des

\section{Introduction}

This contribution is part of our joint enterprise to come to a diachronic and synchronic account of unos, a Spanish determiner that has received a fair amount of attention over the last two decades (see among others Villalta 1994, Laca \& Tasmowski 1996, Gutiérrez-Rexach 2001, 2003, López-Palma 2007, Martí 2008, Le Bruyn 2010, Pozas-Loyo 2010 and Alonso-Ovalle \& Menéndez-Benito 2012). The ultimate goal of this enterprise is to further our understanding of articles and of referentiality within the nominal domain.

The specific question we try to answer in this contribution is whether we could exploit the difference between inclusive (individual atoms and sums/groups) and exclusive (sums/groups only) plurality to understand the differences we find between two determiners that each have been claimed to be plural indefinite articles: Spanish unos (see e.g., Lapesa 2000 [1973]) and French des (see e.g., Grevisse \& Goosse 1993).

On the basis of a study of indefinite singular articles, we start in section 2 by making a provisional list of properties we expect indefinite articles (singular or plural) to have. Section 3 argues that these properties correspond exactly to those we find for French des. Sections 4 and 5 bring in the issue of inclusive/exclusive plurality and argue that the list of properties given in section 2 has to be adapted. These sections furthermore argue that the differences between French des and (at

* Bert gratefully acknowledges the support of the Netherlands Organisation for Scientific Research (NWO), grant 275-80-006. Both Julia and Bert wish to express their gratitude to Violeta Vázquez Rojas Maldonado for her useful comments on the Spanish examples.

C2014 Le Bruyn \& Pozas-Loyo 
least some variants of) Spanish unos can indeed be reduced to the inclusive/exclusive distinction.

\section{The indefinite singular article}

In order to get a provisional list of properties we expect indefinite plural articles to have, we make a small detour via indefinite singular articles, which - be it sometimes indirectly - have been studied in more detail. We single out four properties, the first two of which we take to be intimately related.

a. Krifka (2004) notes that the indefinite singular article is different from the numeral one (its etymological antecedent) in that $a$ has no ties with the number scale. This explains the contrast between $a$ and one in (1):

(1) How many students came to see you?

a. \# A student came to see me.

b. One student came to see me.

Note that $a$ behaves parallel to the definite article (see (2)) and unlike most other indefinite determiners (de Swart 2006). Examples of the latter include some, several, three, etc.

(2) How many students came to see you?

a. \# The students came to see me.

b. Some/Several/Three students came to see me.

b. Because of the fact that the indefinite singular article is not connected to the number scale (nor to any qualitative scale, as far as we know), we expect it not to give rise to partitive implicatures. This is as required: (3a) by no means implicates that there were students who didn't come to see me whereas (3b) does.

(3) a. A student came to see me.

b. One student came to see me.

c. Farkas (2002) notes that the indefinite singular is different from other determiners like singular some in that it can combine with most any operator (unless the operator requires a plural). She accounts for this contrast by introducing extra restrictions for some, that would be absent for $a$. One clear contrast between the two determiners is that $a$, but not some, can easily occur in the scope of a generic operator. This is illustrated in (4): whereas (4a) is fine on a generic reading, (4b) can only get a taxonomic reading. 
Plural indefinite articles: The case of unos and des

(4) a. A seagull lays eggs in the sand. (Farkas 2002: ex. 27)

b. \# Some seagull lays eggs in the sand.

d. Chierchia (1998) notes that articles are in complementary distribution with covert type-shifts: languages that have articles won't allow bare nominals to undergo the type-shifts the articles instantiate covertly. For indefinite articles it's the existential type-shift which would be at play. The existence of the singular indefinite article is said to block singular bare indefinites. This property is illustrated in (5):

(5) $\quad$ I saw *(a) dog.

The above properties are all subsumed by the following simple semantics that only attributes existential quantification to $a$ :

$$
\lambda \mathrm{P} \lambda \mathrm{Q} \exists \mathrm{x}(\mathrm{P}(\mathrm{x}) \& \mathrm{Q}(\mathrm{x}))
$$

Property d. follows straightforwardly. Properties a. through c. follow from the absence of a richer semantics.

\section{French des}

Standard wisdom has it that des is a plural indefinite article. In this section, we argue that standard wisdom is right. In sections 3 and 4, we further argue that Spanish unos — at least in some variants of Spanish — should also be attributed article status.

The four properties identified in section 2 carry over to des virtually without further qualifications:

a. Des cannot be used in an answer to a how many question and can therefore be said to have no links with the number scale:

(7) How many students came to see you?

*Des étudiants sont venus.

'DES students have come.'

b. Des does not - by itself - give rise to any partitive readings. (8), for instance, by no means implicates that there are students who didn't come:

(8) Des étudiants sont venus. [no partitive implicature]

'DES students have come.'

c. Des is compatible with most any operator. In (9) we illustrate with a generic one: 
(9) Des lignes parallèles ne se coupent jamais.

'DES parallel lines never meet.'

As an aside, we note that Romance languages are different from English in that they use plural definites and not bare plurals (or their corresponding article variants) to refer to kinds (see e.g., Dobrovie-Sorin \& Laca 2003). The generic flavor of generic sentences with des is consequently the same as the one we find in generic sentences with the singular indefinite. It's then not really surprising that we find some kind of competition between singular and plural indefinites (Corblin 1987): French will typically prefer to use the indefinite singular in generic sentences without kind reference unless plurality is at issue (as would be the case in (9)).

d. French doesn't allow for indefinite bare plurals:

J'ai vu *(des) chiens.

'I saw (DES) dogs.'

The above properties strongly suggest that des is indeed a plural indefinite article. The only potential problem for an article analysis comes from the fact that it displays - at least to a certain extent — positive polarity behavior. This behavior pops up in (normative) variants that use de instead of des in the scope of negation:

(11) Jean n'a pas acheté d'appartements.

'Jean didn't buy DE apartments.'

(12) Jean n'a pas acheté des appartements.

'Jean didn't buy DES apartments.'

Whereas the DE variant states that Jean didn't buy any apartments, the DES variant states that there are apartments that Jean didn't buy, allowing for there to be apartments that Jean did buy.

We take the positive polarity behavior of des not to pose a problem for an article analysis, as it can be understood in the light of a general tendency to avoid the use of determiners in the scope of negation. The relevant insight comes from dynamic semantics: determiners are used to introduce discourse referents and to allow for their subsequent anaphoric pickup. Given that discourse referents introduced in the scope of negation are not available for anaphoric pickup, it seems reasonable to expect languages to avoid the use of full-fledged determiners in the scope of negation wherever an alternative is available. A similar intuition can explain why a preposition like without is one of the most likely ones to occur with a (singular) bare noun and why —outside the prepositional domain - the scope of negation sometimes allows for singular bare nouns: 
Plural indefinite articles: The case of unos and des

(13) They were reportedly arrested without warrant several days after the demonstrations. (British National Corpus)

(14) Non c'era studente in giro. (Benincà 1980)

'There wasn't student around.'

\section{Plurality flavors}

On the basis of the evidence presented in section 3, we could propose the following semantics for plural indefinite articles and present des as one of the instantiations of this type of expression:

\section{$\lambda \mathrm{P} \lambda \mathrm{Q} \exists \mathrm{x}(\operatorname{plural}(\mathrm{x}) \& \mathrm{P}(\mathrm{x}) \& \mathrm{Q}(\mathrm{x}))$}

The above semantics, however, remains implicit about what it means to be plural, an issue that should not be taken lightly, given the recent literature on the interpretation of plurality in which it has become standard to distinguish between inclusive plurality (individual atoms and sums/groups) and exclusive plurality (only sums/groups). Our proposal is to explore the idea that both types of plurality can give rise to indefinite articles. This section presents the semantics we assume for the two types of articles and identifies des as an inclusive and unos as an exclusive plural indefinite article.

\subsection{The semantics of plural indefinite articles}

We assume the following semantics for inclusive plurality:

$$
\lambda \mathrm{P} \lambda \mathrm{x}\left({ }^{*} \mathrm{P}(\mathrm{x})\right)
$$

With built-in existential closure, this gives us the basic semantics for inclusive plural indefinite articles:

$$
\lambda \mathrm{P} \lambda \mathrm{Q} \exists \mathrm{x}(\mathrm{P}(\mathrm{x}) \& \mathrm{Q}(\mathrm{x}))
$$

Our semantics for the exclusive plural indefinite article is modeled on that of standard plural DPs, which we take to be group denoting expressions:

$$
\lambda \mathrm{P} \lambda \mathrm{Q} \exists \mathrm{X}\left({ }^{*} \mathrm{P}(\mathrm{X}) \& \mathrm{Q}(\uparrow \mathrm{X})\right)
$$

\subsection{Des is inclusive, unos exclusive}

The inclusive plural nature of des is known from the literature (Bosveld-de Smet 1998, de Swart 2006, Spector 2007, among others) and is illustrated in (19): 
As-tu vu des enfants?

'Have you seen DES children?'

Yes, I saw one.

This leaves us with the question whether there is an instantiation of exclusive plural indefinite articles. In section 5 we argue that unos - at least in some variants of Spanish-qualifies. Its exclusive nature is illustrated in (20):

(20) ¿Viste a unos niños jugando en el patio? (Martí 2008: 5)

'Did you see UNOS children play in the garden?'

\#Yes, I saw one.

\section{Spanish unos}

The properties of plural indefinite articles that hold for des also hold for unos except for one, viz., that Spanish differs from French in allowing for bare plurals (see (24)). Examples (21) through (23) furthermore show, respectively, the lack of a connection between unos and the number scale, its lack of partitive implicatures and its compatibility with a generic operator.

(21) How many students came to see you?

*Unos estudiantes han venido.

'UNOS students came.'

(22) Unos estudiantes han venido. [no partitive implicature]

'UNOS students came.'

(23) Unas líneas paralelas nunca convergen entre sí.

'UNOS parallel lines never converge.'

(24) He visto (unos) perros.

'I saw (UNOS) dogs.'

Perhaps surprisingly, the fact that unos doesn't block the existential type shift for bare plurals is expected. Indeed, given that Spanish bare plurals instantiate inclusive plurals and unos an exclusive plural, there is no reason to expect unos to block argumental bare plurals.

In the remainder of this section, we look into three properties of unos that would seem to make an article analysis less viable. We argue that two of them follow (directly or indirectly) from the exclusive plural nature of unos. For the third one, we show that there is language-internal variation and sketch analyses for both variants that are compatible with an article analysis. 
Plural indefinite articles: The case of unos and des

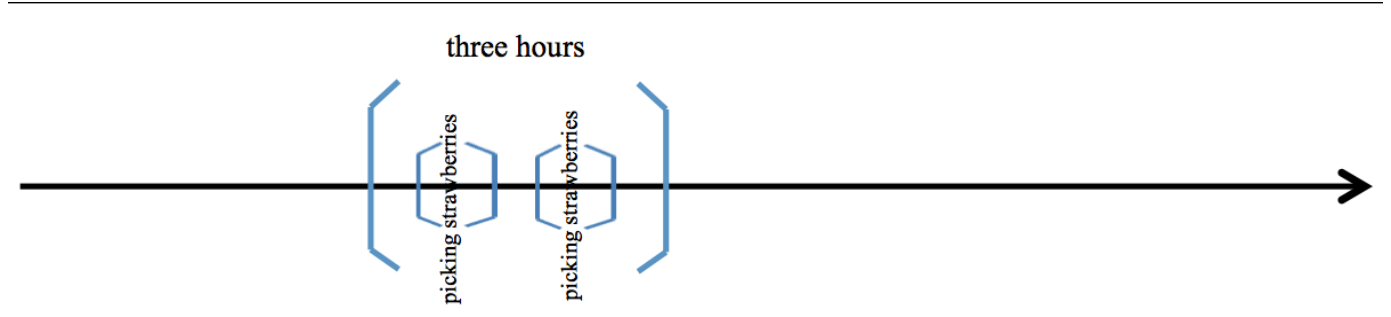

Figure 1 For-adverbials intervals.

\subsection{Unos and for-adverbials}

The first property is the specific behavior of unos when combined with for-adverbials:

?? He recogido unas fresas durante tres horas.

'I picked UNOS strawberries for three hours.'

We note that this behavior is different from that of bare plurals, as shown in (26a, 26b), as well as from that of des, as shown in (26c), and could consequently be considered surprising. ${ }^{1}$

(26) a. I picked strawberries for three hours.

b. He recogido fresas durante tres horas. 'I picked strawberries for three hours.'

c. J'ai cueilli des fraises pendant trois heures.

'I picked DES strawberries for three hours.'

We propose to derive the difference between des and unos from the inclusive/exclusive distinction. In order to do so we first spell out our analysis of foradverbials.

We follow Dowty (1979) in assuming that for-adverbials identify an interval and require the predicate (verb + object) to hold at all (relevant) subintervals. As shown in Figure 1, picking strawberries for three hours would e.g., identify a three hour interval and would require the predicate picking strawberries to hold both at the three hour interval and at all (relevant) subintervals.

What is left then is to determine what a relevant subinterval should be. One proposal would be to take subintervals that are sufficiently large so as to qualify

1 Even though we don't work this out here, we do want to note that the behavior of unos forces us to prefer a Dowty-style analysis of for-adverbials over the one proposed by Krifka (1989). We leave a more extensive argumentation for future work. 
as subintervals at which the verb can be true. This would mean that the atoms of the verb denotation would identify the size of the subintervals. We argue that this proposal can be extended by including the atoms of the object noun denotation, making the subinterval size dependent on what would seem to be natural units for counting events.

With our analysis of for-adverbials in place, it's not difficult to see how the behavior of unos, des and bare plurals follows: given that des and bare plurals are inclusive plurals, a predicate like picking (des) strawberries is expected to be compatible with for-adverbials because it can be true of a larger interval while at the same time being true of the relevant subintervals. The same doesn't hold for picking UNOS strawberries as this can only be true of larger intervals.

As an aside, we note that we expect English some to function like unos, but not because of its exclusive plural nature. Some is indeed crucially different from unos in that it comes with a (vague) cardinality specification as is illustrated in its different behavior in answers to how many questions (see example (2)).

How many students came to see you?

Some students came to see me.

\subsection{Unos and positive polarity}

Unos has been claimed to display positive polarity behavior. This is illustrated in example (28), taken from Laca \& Tasmowski (1996: 121):

(28) A la reunión no asistieron unos profesores. at the reunion not assist UNOS professors

'Some professors didn't attend the reunion.' [unos $>$ no / *no $>$ unos]

As we noted earlier for des, we take positive polarity behavior to be a consequence of the availability of alternatives without determiners ( $d e$ for French des and the bare plural for Spanish unos) and consequently don't take this behavior to endanger an article analysis.

Indirectly, the fact that unos — because of its exclusive plural nature - doesn't block argumental bare plurals, can then be taken to be responsible for its own positive polarity behavior.

\subsection{Unos and collective readings}

Unos subjects in Peninsular Spanish have been claimed to have a preference for collective readings (Villalta 1994, Gutiérrez-Rexach 2001,2003, López-Palma 2007, Martí 2008, Alonso-Ovalle \& Menéndez Benito 2012), a property that des lacks. 
Plural indefinite articles: The case of unos and des

In this section, we provide an overview of the (conflicting) data in the literature and propose a sketch of an analysis without, however, making any strong claims. We then turn our attention to Mexican Spanish and argue that unos in this variant behaves as we would expect, in a first approximation, an article to behave, viz., to allow for both distributive and collective readings.

\subsubsection{The data from the literature}

An often cited paper that, at least to our knowledge, has never been published is Villalta 1994. We reproduce here the crucial fragments: ${ }^{2}$

[Beginning of Villalta (1994) quote.]

Several examples show that unstressed unos in subject position blocks the distributive reading. Examples (29)-(32) only allow the collective reading:

(29) Durante la mudanza, unos hombres levantaron una mesa.

During the move, some men lifted a table.

'During the move, a group of men lifted a table.'

(30) Unos hombres compraron un billete de lotería.

Some men bought a ticket of lottery.

'A group of men bought a lottery ticket.'

(31) Este año, unos estudiantes publicaron un artículo.

This year, some students published an article.

'This year, a group of students published an article.'

(32) \# Unos hombres se pusieron una camisa.

UNOS men SE put a shirt

'Some men put on a shirt.'

In example (29) there can only be one table that has been lifted, in (30) there is only one lottery ticket that has been bought and in (31) there is only one article that has been published by the whole group. Notice that the example (32) is pragmatically odd because the only plausible reading is the distributive reading: it is difficult to imagine a group of men putting on one shirt together.

2 This paper was presented at Going Romance VIII (1994). Note that for ease of reference we however adapt the numbering of the examples. 
$[\ldots]$

Notice now that an example like (33), where unos $\mathrm{N}$ combines with an inherent distributive predicate, is not a counter-example to the claim that unos $\mathrm{N}$ disallows distributive readings: the same is in fact possible for collective NPs, as shown in (34):

(33) Unos niños dormían en el jardín.

'Some children were sleeping in the garden.'

(34) Un grupo de niños dormía en el jardín

'A group of children was sleeping in the garden'.

This last example shows that inherent distributive predicates can also apply to collective NPs (which do not allow for distributive readings). Thus, the possibility of unos $\mathrm{N}$ showing up in these contexts is not unexpected.

$[\ldots]$

$[\mathrm{U}]$ nos $\mathrm{N}$ can combine with an explicit distributive operator, cada uno (each), and the distributive reading is then the only possible reading, as illustrated in (35):

(35) Unos estudiantes publicaron un artículo cada uno.

Some students published an article each one.

'Some students each published an article.'

[End of quote.]

The facts Villalta (1994) presents can be summarized as follows: unos leads to collective readings with mixed predicates (see (29) to (32)) and it leads to distributive readings with inherently distributive predicates (see (33) to (35)). ${ }^{3}$ Even though Villalta does not provide examples with an inherently collective predicate, we assume that she would have claimed it to be compatible with unos DPs as well. To account for these data, one could make the following assumptions:

(36) a. Standard plural indefinite DPs are ambiguous between a group and a sum denotation.

b. Unos is different in only allowing for a group denotation.

c. Verbal predicates come in three guises: (i) those that can only take group atoms, (ii) those that can only take individual atoms and (iii) those that can take both group and individual atoms.

3 We take cada uno to transform any predicate into an intrinsically distributive predicate. 
Plural indefinite articles: The case of unos and des

d. Verbal predicates that can only take individual atoms can shift to a version with a built-in ungrouping operator when combining with group denoting DPs.

On the basis of these assumptions, the facts follow straightforwardly. Unos DPs can directly combine with predicates that only take group atoms, a combination that leads to collective readings. The clash that pops up when we combine unos DPs with predicates that only allow for individual atoms is resolved by the predicate shift that introduces an ungrouping operator, leading to a distributive reading. No clash pops up when unos DPs are combined with mixed predicates and there will consequently be no shift. The resulting reading is consequently a collective one.

The analysis sketched above makes unos into a special determiner within the plural indefinite paradigm, but still allows us to maintain that unos is a more basic determiner than the others in the sense that the ability to generate a sum interpretation can be modelled as a supplementary ingredient. An article analysis would consequently not be endangered.

Another view on unos is defended by Gutiérrez-Rexach in a series of publications. For concreteness, we'll focus on the facts presented in Gutiérrez-Rexach 2003 and we will oppose them to the ones in Villalta 1994.

Contra Villalta 1994, Gutiérrez-Rexach (2003) claims that unos DPs cannot appear in the subject position of intrinsically distributive predicates. He provides the following examples: ${ }^{4}$

* Unos estudiantes se pusieron los pantalones. (2003: 427)

UNOS students themselves put the trousers

'Some students put on their trousers.'

(38) Unos estudiantes comieron una tarta (*cada uno). (2003: 430)

UNOS students ate a cake (*each one)

'Some students each ate a cake.'

In agreement with Villalta (1994), Gutiérrez-Rexach (2003) claims that unos DPs are compatible with collective predicates and can only lead to collective readings with mixed predicates.

(39) Unos estudiantes se

reunieron en el pasillo. (2003: 427)

UNOS students themselves gather in the corridor

'Some students gathered in the corridor'.

4 Gutiérrez-Rexach (2003) actually doesn't state that this judgement goes against Villalta (1994). In fact, he actually states that this judgement is in accordance with that of Villalta. 
(40) Unos estudiantes levantaron una mesa. (2003: 430)

UNOS students lifted a table

'Some students (together) lifted a table'/*'Some students (each) lifted a table'.

The crucial difference between Villalta (1994) and Gutiérrez-Rexach (2003) then is that Villalta claims that unos DPs are compatible with intrinsically distributive predicates, whereas Gutiérrez-Rexach claims they are not.

To account for unos while respecting the data presented by Gutiérrez-Rexach is difficult, not only within an article analysis but also more generally because Gutiérrez-Rexach's intuition boils down to stating that there is no way to recover the individual atoms that underlie the group atoms the referents of unos DPs consist of. This surprising intuition has not really found support in the literature. López-Palma (2007) e.g., claims that the group atoms unos DPs introduce can be accessed:

A cluster-denoting expression [i.e. a group denoting expression] can become transparent, and its atoms can be accessible to syntactic operations if the speaker gives a sufficiently rich description of the group that would enable him to individuate the atoms. The marked distributive reading, which may be obtained when the indefinite has a specific interpretation, can be favored by the deictic interpretation of tense, the informative structure, the syntactic structure, or by the presence of identifying nominal modifiers, like a relative sentence complement, or certain adjectives. (López-Palma 2007: 259)

López-Palma argues that unos allows for an ungrouped (and hence for a distributive) interpretation in a number of contexts that she subsumes under the label 'specific'. Specificity being typically speaker-defined (see e.g., Fodor \& Sag 1982), one could however wonder whether the specificity criterion is not more pragmatic than semantic. Indeed, if the speaker intends to refer specifically, it's unclear why he/she would have to mark this explicitly, especially when the verbal predicate already indicates that a 'specific' (ungrouped) interpretation should be at play.

This brings us to Martí (2008) who notes, in agreement with Villalta (1994), that unos DPs are compatible with inherently collective and inherently distributive predicates:

(41) Unos chicos se reunieron en la oficina. (Martí 2008: 23) UNOS boys themselves gathered in the office

'Some boys gathered in the office'. 
Plural indefinite articles: The case of unos and des

(42) Unos chicos se pusieron los pantalones al llegar al UNOS boys themselves put the trousers at-the arriving at-the gimnasio. (Martí 2008: 23)

gym

'Some boys put on their trousers when they arrived at the gym.'

Martí's basic intuition is that unos DP subjects are not imposing a collective reading, but rather a reading in which the agents do things "together". This is reminiscent of what Villalta notes about example (33):

[O]bserve that unos $\mathrm{N}$ has "group" behavior in the sense of Lasersohn (1991): when collective action is impossible (when the NP combines with an inherent distributive predicate), the interpretation of unos $\mathrm{N}$ necessarily requires spatio-temporal proximity of the participants. (Villalta 1994)

In order to implement these intuitions, only a small change in the assumptions in (36) would be necessary, viz., that the ungrouping shift hinted at in (36d) should come with the extra requirement that the events the members of the group are said to be the (individual) agents of should be spatio-temporally close to one another. The "group" effect is then transferred from the subject DP to the verbal predicate. We note that this would not affect the semantics of unos DPs. ${ }^{5}$

As we said at the beginning of this section, we don't want to make any strong claims about the collectivity/distributivity of Peninsular Spanish unos. What we hope to have done though is to give a fair overview of existing claims and to sketch how, on the basis of the intuitions of Villalta (1994) and Martí (2008), we could maintain that Peninsular unos counts as an indefinite article.

\subsubsection{Unos in Mexican Spanish}

The case of Mexican unos is significantly simpler than the one of Peninsular unos. This is due to the fact that the literature doesn't report any conflicting judgements but also - we would like to claim - to the fact that intuitions are very clear and in line with an analysis that would take unos to behave like any other indefinite determiner in being compatible with all types of predicates, allowing for collective and distributive readings with mixed predicates (see (43)), not requiring any spatiotemporal adjacency when allowing both for collective and distributive readings, and

5 Note also that a similar group-transfer effect is not expected for other indefinite plural DPs combining with inherently distributive predicates. This is due to the fact that other indefinite plural DPs always have a sum interpretation at their disposal anyway (see assumption (36a)). 
not requiring any spatio-temporal adjacency with inherently distributive predicates (see (44)).

(43) a. Unos estudiantes adoptaron un perro. Le pusieron Paul. [collective] UNOS students adopted a dog him named Paul 'Some students adopted a dog. They named him Paul.'

b. Unos estudiantes adoptaron un perro. El de María es negro y el de UNOS students adopted a dog the of María is black and the of Silvia es gris. [distributive]

Silvia is grey

'Some students adopted a dog. María's is black and Silvia's is grey.

(44) Unos estudiantes míos de historia vinieron ayer al despacho. UNOS students mine of history came yesterday to_the office

'Some students of my history class came to my office yesterday.'

The first sentences of (43) contain a mixed predicate. The continuations in (43a) and (43b) follow-up on the collective and the distributive readings respectively. In Peninsular Spanish, (44) has been claimed to only allow for a reading in which all the students came at the same time (Martí 2008: 21). In Mexican Spanish however, the students might have come at different times (be it of course within the timeframe provided by ayer).

The facts in (43) and (44) show that any account of the collective/distributive contrast that has been proposed for plural indefinite determiners can easily be extended to Mexican Spanish unos. This means that no special provisos have to be made for this determiner and that an article analysis is easy to maintain.

In this section, we have shown that there are at least two variants of Spanish one should take into account when assessing the article status of unos, viz., Peninsular and Mexican Spanish. For Mexican Spanish, the article status of unos is straightforward in the sense that it doesn't differ from other indefinite determiners and there's consequently no reason to assume that its semantics should be complicated beyond what we have claimed in section 4.2. Peninsular unos is another matter and would require us to make a certain number of assumptions. We have however refrained from working these out in detail given that the interpretational facts connected with Peninsular Spanish are far from agreed upon in the literature. What is crucial for us though is that there is a variant of unos that behaves exactly in the way we would expect an exclusive plural indefinite article to behave. 
Plural indefinite articles: The case of unos and des

\section{Summary and conclusion}

In this contribution, we have argued that both des and unos (esp. Mexican unos) have the properties we expect plural indefinite articles to have, modulo the distinction between inclusive and exclusive plurality. In particular, we have argued that the two are expected to differ in blocking and aspectual properties. Next to an exploration of the viability of the idea that plural indefinite articles come in two guises, the present contribution can also be interpreted as a defense of an analysis of unos as the least marked plural indefinite determiner in Spanish, in line with the work by Martí (2008) and Alonso-Ovalle \& Menéndez Benito (2012).

\section{References}

Alonso-Ovalle, Luis \& Paula Menéndez-Benito. 2012. Indefinites, dependent plurality, and the viability requirement on scalar alternatives. Journal of Semantics 30(1). 65-102.

Benincà, Paola. 1980. Nomi senza articolo. Rivista di grammatica generativa 5. 51-63.

Bosveld-de Smet, Leonie Marie. 1998. On mass and plural quantification. The case of French des/du-NPs: University of Groninger, PhD dissertation.

Carmen, Dobrovie-Sorin \& Brenda Laca. 2003. Noms sans determinants. In Les Langues Romanes, Problèmes de la Phrase Simple, 235-281. CNRS Editions.

Chierchia, Gennaro. 1998. Reference to kinds across languages. Natural Language Semantics 6. 339-405.

Corblin, Francis. 1987. Indéfini, Défini et Démonstratif. Genève: Librairie Droz.

De Swart, Henriette. 2006. Aspectual implications of the semantics of plural indefinites. In Svetlana Vogeleer \& Liliane Tasmowski (eds.), Non-Definiteness and Plurality, 161-189. Amsterdam: John Benjamins.

Dowty, David R. 1979. Word Meaning and Montague Grammar. The Semantics of Verbs and Times in Generative Semantics and in Montague's PTQ. Dordrecht: Reidel.

Farkas, Donkas. 2002. Varieties of indefinites. In Bendan Jackson (ed.), Semantics and Linguistic Theory (SALT) 12, 59-83. Ithaca, NY: CLC Publications.

Fodor, Janet Dean \& Ivan A. Sag. 1982. Referential and quantificational indefinites. Linguistics and Philosophy 5. 355-98.

Grevisse, Maurice \& André Goosse. 1993. Le Bon Usage. Paris: Duculot 13th edn.

Gutiérrez-Rexach, Javier. 2001. The semantics of Spanish plural existential determiners and the dynamics of judgment types. Probus 13.113-154.

Gutiérrez-Rexach, Javier. 2003. La Semántica de los Indefinidos. Madrid: Visor Libros. 
Krifka, Manfred. 1989. Nominal reference, temporal constitution and quantification in event semantics. In J. van Benthem R. Bartsch \& P. von Emde Boas (eds.), Semantics and Contextual Expression, CSLI Publications.

Krifka, Manfred. 2004. Bare NPs: kind-referring, indefinites, both, or neither? In Robert B. Young \& Yuping Zhou (eds.), Semantics and Linguistic Theory (SALT) 13, 180-203. Ithaca, NY: CLC Publications.

Laca, Brenda \& Liliane Tasmowski. 1996. Indéfini et quantification. Recherches Linguistiques de Vicennes 25. 107-128.

Lapesa, Rafael. 2000 [1973]. Un, una como artículo indefinido en español. In Rafael Cano Aguilar \& Ma. Teresa Echenique Elizondo (eds.), Estudios de morfosintaxis histórica del español, vol. II, 477-487. Madrid: Gredos.

Le Bruyn, Bert. 2010. Indefinite Articles and Beyond. LOT.

López Palma, Helena. 2007. Plural indefinite descriptions with unos and the interpretation of number. Probus 19. 235-266.

Martí, Luisa. 2008. The semantics of plural indefinite noun phrases in Spanish and Portuguese. Natural Language Semantics 16. 1-37.

Pozas-Loyo, Julia. 2010. The Development of the Indefinite Article in Medieval and Golden-Age Spanish. London: Queen Mary, University of London, PhD dissertation.

Spector, Benjamin. 2007. Aspects of the pragmatics of plural morphology: On higher-order implicatures. In Uli Sauerland \& Penka Stateva (eds.), Presuppositions and Implicatures in Compositional Semantics, 243-281. New York: Palgrave-Macmillan.

Villalta, Elisabeth. 1994. Plural Indefinites in Spanish and Distributivity. Unpublished ms. Université Paris 8.

Bert Le Bruyn

Trans 10

3512 JK Utrecht

The Netherlands

B.S.W.LeBruyn@uu.nl
Julia Pozas-Loyo

El Colegio de México

Camino al Ajusco 20

México, D.F. 10740

jpozas@colmex.mx 